\title{
PENGEMBANGAN MULTIMEDIA PEMBELAJARAN PRAKTIK INDIVIDU INSTRUMEN POKOK DASAR SISWA SMK DI BIDANG KEAHLIAN KARAWITAN
}

\author{
Ismalik Perwira Admadja \\ Program Studi Pendidikan Teknologi dan Kejuruan PPsUNY \\ ismalikperwira@yahoo.com \\ Eko Marpanaji \\ Fakultas Teknik Universitas Negeri Yogyakarta \\ eko@uny.ac.id
}

\begin{abstract}
Abstrak
Penelitian ini bertujuan untuk: (1) menghasilkan multimedia pembelajaran pada mata pelajaran praktik individu instrumen pokok dasar, (2) mengetahui kelayakan multimedia pembelajaran pada mata pelajaran praktik individu instrumen pokok dasar, dan (3) mengetahui peningkatan hasil belajar siswa menggunakan multimedia pembelajaran pada mata pelajaran praktik individu instrumen pokok dasar. Metode penelitian yang digunakan adalah metode penelitian dan pengembangan dengan desain model pengembangan Stephen M. Alessi dan Stanley R. Trollip. Langkah-langkah pengembangannya yaitu: (1) perencanaan; (2) desain; dan (3) pengembangan. Teknik analisis data untuk uji coba produk menggunakan statistik deskriptif. Hasil penelitian menunjukkan bahwa: (1) ditinjau dari aspek media dinilai "Sangat Baik" dengan skor 4,27 oleh ahli media;(2) ditinjau dari aspek materi dinilai "Sangat Baik" dengan skor 4,47 oleh ahli materi; (3) ditinjau dari aspek penggunaan dinilai "Sangat Baik" dengan skor 4,23 oleh siswa; (4) peningkatan hasil belajar siswa menunjukkan kenaikan rerata skor siswa kelas yang menggunakan multimedia sebesar 31,53 sedangkan kelas yang tidak menggunakan multimedia meningkat sebesar 20,11 .
\end{abstract}

Kata kunci: pengembangan, pembelajaran, multimedia pembelajaran, kelayakan.

\section{DEVELOPING LEARNING MULTIMEDIA OF INDIVIDUAL PRACTICE IN FUNDAMENTAL MUSIC INSTRUMENT FOR SMK STUDENTS IN THE EXPERTISE OF KARAWITAN}

\begin{abstract}
The purposes of this research were: (1) to produce multimedia learning on the subject of individual practice in fundamental music instrument; (2) to determine the appropriateness of the learning multimedia in the subject of individual practice in fundamental music instrument; and (3) to determine the improvement in the students' learning outcomes from the use of multimedia in teaching the subject of individual practice in fundamental music instrument.This research was a research and development, with the development model design by Alessi and Trollip. The development stages were as follows: (1) planning; (2) design; and (3) development. The data of the try-out of the product was analyzed using descriptive statistics. The results showed that: (1) the media aspects were rated "very good" with a score of 4.27 by the media expert; (2) the material aspects were rated "very good" with a score of 4.47 by the materials expert; (3) the aspects of using product were rated "very good" with a score of 4.23 by the students; (4)the improvement of the students' learning outcomes in the class using the multimedia showed a mean score increase of 31.53 which was greater than that of the nonmultimedia class which was only 20.11.
\end{abstract}

Keywords: development, learning, learning multimedia, appropriateness 


\section{PENDAHULUAN}

Kemajuan ilmu dan teknologi yang mengglobal telah berpengaruh dalam segala aspek kehidupan baik di bidang ekonomi, politik, kebudayaan seni dan bahkan di dunia pendidikan. Kemajuan ilmu pengetahuan dan teknologi telah memberikan warna tersendiri bagi dunia pendidikan pada umumnya serta mampu mengubah paradigma lama pembelajaran dengan menampilkan teknologi sebagai alat bantu mengajar penunjang proses pembelajaran. Adeyemo (2010, pp. 48-59) mengatakan bahwa teknologi informasi dan komunikasi memberikan pengaruh yang besar pada kegiatan belajar mengajar dan juga membuat pembelajaran menjadi menarik bagi siswa, misalnya multimedia pembelajaran yang menerapkan perkembangan dalam proses pembelajaran.

Multimedia pembelajaran merupakan suatu alat atau perantara yang dapat menyajikan, menyampaikan pesan serta membangkitkan keinginan dan membangkitkan motivasi siswa untuk belajar dengan menggabungkan dan mensinergikan berbagai elemen, yaitu teks, grafis, foto, video, animasi, musik, dan narasi yang saling terhubung memungkinkan pemakai melakukan interaksi dan komunikasi. Hal ini seperti yang dinyatakan oleh Richard Mayer (dalam Sorden 2005, pp. 263-279) bahwa "Pembelajaran dengan multimedia didefinisikan sebagai sebuah presentasi materi ajar dengan menggunakan kata-kata dan gambar-gambar". Dengan adanya multimedia pembelajaran, siswa dapat lebih berminat dan termotivasi dalam belajar, sehingga daya serap siswa mengenai meteri yang sedang diajarkan akan meningkat.

Saat ini banyak mata pelajaran di sekolah yang menggunakan media sebagai salah satu alternatif pengembangan multimedia pembelajaran. Dalam pembelajaran menggunakan multimedia, peserta didik diajak untuk berpartisipasi aktif dalam kegiatan pembelajaran, meskipun ajakan untuk ikut berpartisipasi tersebut hanya bersifat simulasi. Dengan multimedia pembelajaran seolah-olah terjadi komunikasi dua arah antara peserta didik dengan narator yang membawakan materi pembelajaran dalam media audio ataupun audio-visual. Junaidu (2008, pp. 97-107) menunjukkan bahwa pembelajaran menggunakan multimedia berbasis komputer dapat meningkatkan pembelajaran selama proses belajar berlangsung, hal tersebut terlihat dari kepuasan siswa dan motivasi yang lebih tinggi saat belajar menggunakan bahan multimedia serta siswa tidak mudah bosan dan lebih tertarik untuk mengikuti pembelajaran.

Peran peserta didik dengan menggunakan multimedia menjadi sangat menonjol, dan peran guru menjadi tidak terlalu sentral. Peran guru dalam pembelajaran multimedia yaitu menyiapkan bahan ajar dan memberikan penilaian hasil pekerjaan siswa. Pembelajaran menggunakan multimedia sangat cocok untuk kegiatan pembelajaran baik yang bersifat individual maupun kelompok. Namun, jika pemanfaatannya secara individual, maka peserta didik dituntut untuk lebih aktif mencari solusi sendiri atas persoalan-persoalan yang mereka temui. Penggunaan multimedia akan membantu guru untuk menyampaikan dan menjelaskan materi agar lebih menarik dan lebih mudah dipahami peserta didik. Maran, Selvaraj \& Ravikumar (2011, pp. 88-92) yang meneliti tentang penggunaan teknologi multimedia dalam pembelajaran, menyatakan hasil penelitian pembelajaran melalui fasilitas teknologi multimedia lebih efisien dan efektif dalam sistem pendidikan tinggi. Penggunaan multimedia dalam sumber belajar memberikan keuntungan untuk siswa dan pengajar serta dapat memvisualisasi pembelajaran siswa pada pemahaman konsep.

Guru sebaiknya mengupayakan pembaharuan multimedia pembelajaran, agar peserta didik tidak merasa jenuh dengan multimedia pembelajaran yang telah ada. Hung (2005, pp. 282-287) menegaskan bahwa penggunaan teknologi instruksional disesuaikan dengan materi dan lingkungan belajar serta tujuan pembelajaran. Dalam penggunaan teknologi, penelitian ini merekomendasikan guru sebagai penanggung jawab pembelajaran untuk merencanakan pembelajaran dengan matang. Untuk itu media pendidikan dan pengajaran di sekolah-sekolah perlu menyesuaikan kemajuan teknologi penggunaan alat-alat bantu mengajar, audio, visual, dan audio-visual sehingga pembelajaran menjadi lebih efektif dan efisien

Sekolah Menengah Kejuruan (SMK) merupakan satuan pendidikan yang menyelenggarakan pendidikan pada jalur formal, yang mengutamakan pengembangan keterampilan siswa. Menurut Evans (dalam 
Djojonegoro 1998, p.33), pendidikan kejuruan sebagai bagian dari sistem pendidikan yang mempersiapkan seseorang agar lebih mampu bekerja pada satu kelompok pekerjaan atau satu bidang pekerjaan dibanding bidang-bidang pekerjaan lainnya. Artinya, setiap bidang studi adalah pendidikan kejuruan sepanjang bidang studi tersebut dipelajari lebih mendalam dibanding bidang studi lainnya dan kedalaman itu sebagai bekal memasuki dunia kerja.

Peraturan Pemerintah Nomor 17 Tahun 2010 tentang Penyelenggaraan dan Pengelolaan Pendidikan Pasal 80 menyatakan bahwa penjurusan pada SMK, MAK, atau bentuk lain yang sederajat berbentuk bidang keahlian, setiap bidang keahlian terdiri atas 1 (satu) atau lebih program studi keahlian, setiap program studi keahlian terdiri atas 1 (satu) atau lebih kompetensi keahlian. Bidang keahlian pada SMK/MKA meliputi Teknologi dan Rekayasa, Teknologi Informasi dan Komunikasi, Kesehatan, Agribisnis dan Agroteknologi, Perikanan dan Kelautan, Bisnis dan Manajemen, Seni Rupa dan Kriya, Pariwisata, dan Seni Pertunjukan.

SMK N 1 Kasihan, Bantul merupakan sekolah lanjutan bagi siswa-siswi yang mempunyai kebutuhan pendidikan dalam bidang keahlian seni pertunjukan khususnya karawitan. Tujuan pendidikan seni pertunjukan adalah menciptakan tenaga terampil, mandiri dan profesional yang diharapkan setelah lulus dapat langsung berkecimpung dalam dunia kerja bagi peserta didik khususnya di bidang seni pertunjukan. Salah satu kompetensi yang harus dicapai dari bidang seni pertunjukan yaitu mampu memainkan instrumen gender barung pada seni pertunjukan. Untuk mampu memainkan instrumen gender barung, mata pelajaran yang wajib diikuti siswa yaitu Praktik Individu Instrumen Pokok (PIIP) Dasar.

Berdasarkan hasil wawancara dan pengamatan pada sekolah SMK N 1 Kasihan Bantul terdapat beberapa permasalahan dalam pembelajaran PIIP Dasar. Permasalahan yang dihadapi yaitu belum tersedianya bahan ajar dari pemerintah serta proses belajar mengajar yang kurang efektif dan efisien.Permasalahan lain dalam belajar mengajar yaitu guru kurang memanfaatkan teknologi untuk proses belajar mengajar. Hal ini dapat dilihat dari guru yang masih menjelaskan bagian-bagin instrumen gender dengan cara menggambarkan di papan tulis. Dalam proses ini tentunya guru memerlukan waktu yang cukup banyak dalam menggambarkan bagian-bagian instrumen gender. Selain itu, gambar yang dihasilkan guru juga kurang detail mengakibatkan siswa kurang memahami.

Berdasarkan permasalahan-permasalahan yang telah diuraikan maka sangat perlu dibuat multimedia pembelajaran yang menarik, efektif, efisien waktu, dan mudah dalam penggunaannya yaitu multimedia pembelajaran pada mata pelajaran PIIP Dasar. Dengan dibuatnya multimedia pembelajaran ini diharapkan guru mempunyai persepsi dan acuan bahan materi yang sama sehingga tidak terdapat perbedaan materi yang diajarkan. Penggunaan multimedia pembelajaran akan membuat siswa lebih tertarik mengikuti proses belajar mengajar, karena materi yang ada di dalam multimedia pembelajaran dibuat semenarik mungkin dan disisipi dengan animasi yang mendukung materi. Melalui penggunaan multimedia ini guru nantinya tidak perlu menghabiskan waktu untuk menggambar bagian-bagian instrumen gender karena multimedia pembelajaran dapat menyediakan gambaran bagian-bagian instrumen gender secara mendetail.

Pengembangan multimedia pembelajaran menggunakan model pengembangan yang dikembangkan oleh Stephen M. Alessi dan Trolip (2001, pp.407-561). Secara umum model pengembangan multimedia interaktif ini memiliki tiga atribut dan tiga fase, masingmasing atribut dan fase terdiri dari berbagai masalah yang akan dibahas. Ketiga atribut tersebut yaitu atribut standards; ongoing evaluation; dan project management. Tiga fase dalam model pengembangan tersebut yaitu planning, design, dan development. Desain pengembangan Allessi \& Trollip dapat dilihat pada Gambar 1.

Atribut standards adalah titik awal dan dasar dari proyek yang akan dikembangkan. Atribut ongoing evaluation merupakan standar evaluasi yang dilakukan terhadap proyek yang hanya berguna jika pengembang menerapkan secara konsisten di seluruh proyek. Atribut project management merupakan tahapan saat pengembang melakukan kontrol yang tepat terhadap semua aspek pengembangan proyek. 


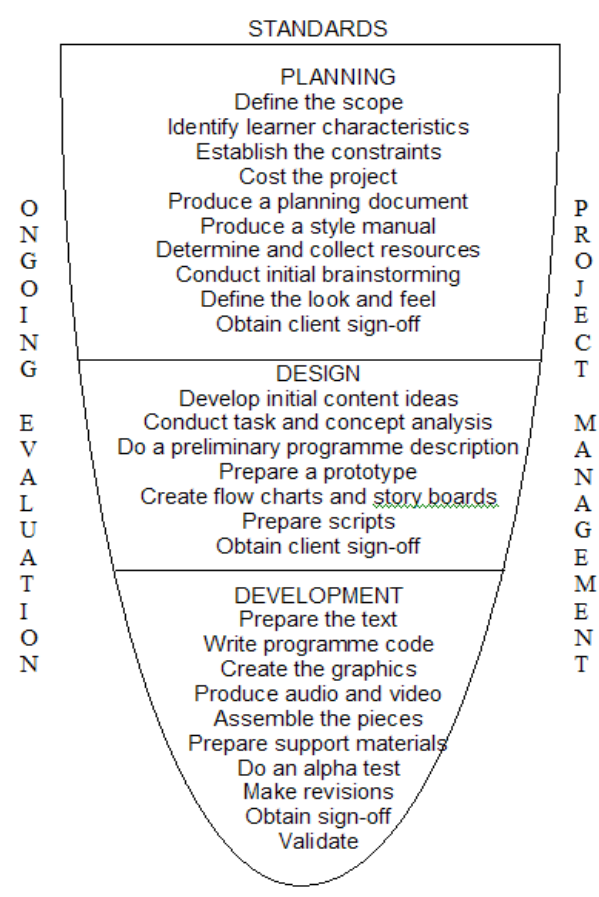

Gambar 1. Desain Pengembangan Allessi \& Trollip (2001)

Tahap perencanaan (planning) merupakan tahapan yang dilakukan oleh pengembang untuk menentukan tujuan dan arah dari pengembangan proyek. Tahap desain (design) merupakan tahapan yang berhubungan dengan ide pengembangan konten awal, yaitu mendeskripsikan pendahuluan program, menyiapkan prototype, serta membuat flowchart dan storyboards. Tahap pengembangan (development) merupakan implementasi dari tahapan desain. Dalam tahapan ini hal-hal yang dilakukan adalah menyiapkan materi, menyiapkan aplikasi pendukung pengembangan, pembuatan bahan audio dan video, penulisan code program, serta melakukan uji coba yang terdiri atas uji alpha, uji beta, dan implementasi. Uji alpha, uji beta dan implementasi dilakukan setelah produk awal selesai.

Tes alpha merupakan tes internal formal, melibatkan pengembang bersama tim, dalam hal ini ahli media, dan ahli materi. Tes ini untuk mengidentifikasi dan mengeliminasi permasalahan produk, prosedur, kesesuaian dengan tujuan (goal), dan alur komunikasi dari multimedia pembelajaran. Proses pengambilan data dari ahli media dan ahli materi dilakukan dengan memberikan instrumen. Kisi-kisi instrumen yang digunakan diambil dari beberapa konsep Alessi \& Trolip (2001, pp.415-417) kemudian konsep tersebut dise- suaikan berdasarkan kebutuhan dalam penelitian. Instrumen untuk ahli media mencakup: (a) desain layar; (b) pengoperasian program; (c) navigasi; dan (d) kemanfaatan. Instrumen untuk ahli materi mencakup: (a) kualitas materi pembelajaran, dan (b) kemanfaatan materi.

Tes beta merupakan tes yang sepenuhnya dilakukan siswa dan pengembang. Tes beta dilakukan setelah revisi tes alpha. Berdasarkan informasi yang diperoleh setelah tes beta maka dilanjutkan dengan revisi produk akhir sehingga produk siap digunakan di kelas nyata pada saat implementasi produk./evaluasi sumatif. Aspek yang dinilai pada tahapan ini terdiri atas: (a) kemudahan produk dioperasikan; (b) kemudahan produk dipelajari isinya; dan (c) kemenarikan tampilan. Implementasi produk atau evaluasi sumatif dilakukan secara formal untuk mengetahui apakah produk dapat digunakan secara lebih luas, di luar situasi sebagaimana pelaksanaan tes sebelumnya. Namun, langkah-langkah dan hal-hal yang dicermati relatif sama dengan pelaksanaan tes beta.

Huang, Dedegikas, dan Walls (2011, pp. 1-9) menunjukkan bahwa kombinasi teknologi multimedia dan desain pembelajaran yang tepat dapat menciptakan lingkungan belajar yang baik menuju pembelajaran efektif. Dengan adanya multimedia pembelajaran ini diharapkan dapat bermanfaat bagi siswa, guru, sekolah dan ilmu pengetahuan. Bagi siswa multimedia dapat menjadikan pembelajaran lebih menarik dan menyenangkan sehingga siswa termotivasi untuk aktif belajar, serta mempermudah siswa dalam memahami materi pembelajaran PIIP Dasar khususnya pada memainkan instrumen gender barung. Manfaat bagi guru multimedia diharapkan dapat membantu guru untuk menyampaikan materi secara efektif dan efisien dalam proses pembelajaran PIIP Dasar dan memotivasi guru untuk membuat multimedia pembelajaran dengan memanfaatkan komputer. Multimedia pembelajaran ini juga bisa menambah media pembelajaran bagi sekolah mengingat belum adanya produk multimedia pembelajaran berbantuan komputer pada mata pelajaran PIIP Dasar khususnya pada memainkan instrumen gender barung.

Tujuan penelitian pengembangan yang hendak dicapai yakni: (1) menghasilkan multimedia pembelajaran untuk mata pelajaran 
PIIP Dasar, (2) mengetahui kelayakan multimedia pembelajaran sebagai media pembelajaran, dan (3) mengetahui, peningkatan hasil belajar penggunaan multimedia pembelajaran pada mata pelajaran PIIP Dasar.

\section{METODE PENELITIAN}

Penelitian ini masuk dalam prosedur R\&D karena hasil penelitian berorientasi pada produk pembelajaran. Model pengembangan yang digunakan oleh peneliti adalah model pengembangan dan desain multimedia yang dikembangkan oleh Allesi dan Trollip (2001, pp. 407-561). Penggunaan model pengembangan ini karena model ini memang dikhususkan untuk mengembangkan multimedia pembelajaran.

Penelitian dan pengembangan ini dilakukan di SMK N 1 Kasihan, Bantul secara bertahap. Pengembangan produk awal dilakukan dari bulan Maret 2014 s/d Juli 2015. Uji coba produk dilakukan pada bulan Agustus dan Oktober 2015. Uji alpha terkait dengan ahli media dan ahli materi dilakukan pada tanggal 12 Agustus 2015 dan 13 Agustus 2015, untuk uji beta dan uji sumatif dilakukan dari tanggal 15 Agustus sampai tanggal 27 Agustus 2015.

Penelitian ini menggunakan tiga subjek coba yaitu: (a) 3 siswa untuk uji beta diambil dari siswa berkemampuan tinggi, sedang, dan rendah yang dipilih oleh guru mata pelajaran; (b) 22 siswa kelas X K1 SMK Negeri 1 Kasihan Bantul sebagai kelas eksperimen; dan (c) 22 siswa kelas X K3 SMK Negeri 1 Kasihan Bantul sebagai kelas kontrol.
Prosedur penelitian pengembangan ini melalui 3 tahap penting yaitu perencanaan (planning), desain (design) dan pengembangan (development). Adapun proses selengkapnya pengembangan multimedia menurut Alessi dan Trollip seperti yang terlihat pada Gambar 2.

Data yang dihasilkan dalam penelitian ini ada dua jenis. Data kualitatif diperoleh saat pengumpulan data untuk kebutuhan pengembangan sistem pada tahapan planning yaitu dengan mewawancarai guru, dan laboran menggunakan pedoman wawancara serta membagikan angket analisis kebutuhan siswa. Data kuantitatif diperoleh dari hasil pretest/ posttes dan uji coba produk. Instrumen pretest dan posttest digunakan untuk mengetahui peningkatan hasil belajar siswa menggunakan multimedia terhadap kelas eksperimen dengan membandingkan kenaikan gain hasil belajar dari kelas kontrol. Instrumen retest diberikan sebelum pertemuan pertama dan postest diberikan pada pertemuan terakhir. Untuk uji coba dimulai dari uji alpha yang dilakukan dengan memberikan instrumen yang spesifik kepada ahli media dan materi, uji beta dilakukan dengan memberikan instrumen kepada tiga siswa kelas X K1, dan uji sumatif dilakukan dengan memberikan intrumen kepada seluruh siswa kelas X K1 sebagai kelas eksperimen. Instrumen-instrumen tersebut sebelumnya telah divalidasi oleh dosen. Kisi-kisi instrumen yang digunakan diambil dari beberapa konsep Alessi \& Trolip (2001, pp.415-417) kemudian konsep tersebut disesuaikan berdasarkan kebutuhan dalam penelitian.

\begin{tabular}{|c|c|c|}
\hline Perencanaan & Desain & Pengembangan \\
\hline $\begin{array}{l}\text { Mendefinisikan } \\
\text { bidang/ruang } \\
\text { lingkup } \\
\text { Mengidentifikasi } \\
\text { karakteristik siswa } \\
\text { Menentukan dan } \\
\text { mengumpulkan } \\
\text { sumber-sumber } \\
\text { Melakukan } \\
\text { brainstorming }\end{array}$ & $\begin{array}{c}\text { Mengembangkan } \\
\text { isi gagasan utama } \\
\text { Melakukan } \\
\text { analisis konsep } \\
\text { dan tugas yang } \\
\text { berkaitan dengan } \\
\text { materi } \\
\text { Membuat } \\
\text { flowcharts dan } \\
\text { storyboards }\end{array}$ & $\begin{array}{c}\text { Menyiapkan teks } \\
\text { Menggabungkan bagian-bagian } \\
\text { Menyiapkan materi-materi pendukung } \\
\text { Membuat program } \\
\text { Melakukan uji alpha } \\
\text { Revisi pertama } \\
\text { Melakukan uji beta } \\
\text { Revisi akhir } \\
\text { Melakukan evaluasi sumatif }\end{array}$ \\
\hline
\end{tabular}

Gambar 2. Prosedur Pengembangan Model Alessi dan Trollip 
Tabel 1. Kisi-kisi Instrumen Ahli Materi

\begin{tabular}{clc}
\hline No & \multicolumn{1}{c}{ Aspek } & $\begin{array}{c}\text { Jumlah } \\
\text { Butir }\end{array}$ \\
\hline 1 & Kualitas materi pembelajaran & 16 \\
2 & Kemanfaatan materi & 3 \\
\hline
\end{tabular}

Tabel 2. Kisi-kisi Instrumen Ahli Media

\begin{tabular}{clc}
\hline No & \multicolumn{1}{c}{ Aspek } & Jumlah Butir \\
\hline 1 & Desain layar & 11 \\
2 & Pengoperasian program & 2 \\
3 & Navigasi & 3 \\
4 & Kemanfaatan & 6 \\
\hline
\end{tabular}

Tabel 3. Kisi-kisi Instrumen Uji Beta

\begin{tabular}{clc}
\hline No & \multicolumn{1}{c}{ Aspek } & Jumlah Butir \\
\hline 1 & $\begin{array}{l}\text { Kemudahan produk } \\
\text { dioperasikan }\end{array}$ & 10 \\
2 & $\begin{array}{l}\text { Kemudahan produk } \\
\text { dipelajari isinya }\end{array}$ & 10 \\
3 & Kemenarikan tampilan & 10 \\
\hline
\end{tabular}

Dalam penelitian R\&D tidak melakukan uji hipotesis. Teknik analisis data dalam penelitian ini menggunakan statistik deskriptif yang berupa pernyataan sangat baik, baik, cukup, kurang, sangat kurang yang diubah menjadi data kuantitatif dengan skala 5 yaitu dengan penskoran dari 1-5. Langkah-langkah dalam analisis data antara lain: (1) mengumpulkan data mentah; (2) pemberian rata-rata skor; (3) skor dikonversikan menjadi nilai dengan skala 5 dengan menggunakan acuan konversi dari Sukardjo (2008, p.101).

Tabel 4. Kriteria Penilaian pada Skala 5 (Sukardjo, 2008).

\begin{tabular}{ccc}
\hline Nilai & Rentang & Kategori \\
\hline 5 & $X>4,08$ & Sangat Baik \\
4 & $3,36<X \leq 4,08$ & Baik \\
3 & $2,64<X \leq 3,36$ & Cukup \\
2 & $1,92<X \leq 2,64$ & Kurang \\
1 & $X \leq 1,92$ & Sangat Kurang \\
\hline
\end{tabular}

Acuan penilaian pada Tabel 4 digunakan untuk menentukan kriteria layak tidaknya produk multimedia yang dikembangkan. Produk multimedia yang dikembangkan ini dapat dikatakan layak sebagai multimedia mata pel- ajaran PIIP Dasar apabila hasil uji coba lapangan minimal termasuk dalam kriteria "Baik".

Analisis terhadap multimedia dalam meningkatkan hasil belajar siswa akan dilakukan dengan membandingkan nilai hasil belajar (posttest) siswa, antara kelas yang menggunakan multimedia pembelajaran dengan kelas yang menggunakan presentasi. Acuan penilaian akan melihat gain dari hasil pretest dan posttest dari dua kelas tersebut (Hake, 1998, p.67) apakah multimedia mampu meningkatkan nilai posttest dari pretest jika dibandingkan dengan hasil posttest dari pretest kelas yang menggunakan presentasi. Karena materi yang diberikan berupa teori dan praktik maka nilai praktek akan ditambahkan dalam posttest untuk analisis data hasil belajar siswa.

\section{HASIL PENELITIAN DAN PEMBAHASAN}

Dalam uji coba produk diperoleh empat jenis data, yaitu data validasi (uji alpha) dari ahli materi dan ahli media, data uji beta, dan data uji sumatif/uji coba kelompok besar. Ahli materi mengevaluasi multimedia pembelajaran hasil pengembangan dari aspek pembelajaran dan aspek materi. Ahli media mengevaluasi multimedia pembelajaran hasil pengembangan dari aspek media. Hasil evaluasi dari ahli materi dan ahli media digunakan untuk merevisi multimedia pembelajaran dan mengukur layak atau tidak layak multimedia yang dikembangkan tersebut untuk diujicobakan di lapangan.

\section{Hasil Uji Alpha}

Tahapan uji alpha terbagi dalam dua bagian yaitu, uji validasi ahli media dan uji validasi ahli materi. Ahli media dalam produk penelitian ini adalah Prof. Herman Dwi Surjono, Ph.D. Beliau adalah dosen multimedia pembelajaran di Pascasarjana Universitas Negeri Yogyakarta. Ahli materi dalam produk penelitian ini adalah Drs. Bambang Suharjana, M.Sn. Beliau dosen fakultas FBS Program Bidang Studi Pendidikan Seni Tari. Uji validasi ahli media adalah proses menilai kelayakan multimedia pembelajaran sedangkan uji validasi ahli materi adalah menilai kelayakan materi yang akan diberikan sebelum di uji cobakan kepada siswa. Penilaian oleh ahli media tersebut dilakukan dengan menggunakan angket. Angket ahli materi untuk 
aspek pembelajaran terdiri atas 22 aspek. Berdasarkan validasi yang dilakukan ahli media dan mengacu pada kriteria penilaian (Tabel 4) dapat diketahui bahwa penilaian terhadap multimedia pembelajaran yang dikembangkan adalah "sangat baik" dengan rerata 4,27. Penilaian ahli media dapat dilihat pada Tabel 5 .

Tabel 5. Hasil Validasi Ahli Media

\begin{tabular}{lcc}
\hline \multicolumn{1}{c}{ Kategori } & Frek. & Prosentase (\%) \\
\hline Sangat Baik & 6 & 27,27 \\
Baik & 16 & 72,73 \\
Cukup & & \\
Kurang & & \\
Sangat kurang & & \\
Jumlah & 22 & 100 \\
\hline
\end{tabular}

Kualitas multimedia pembelajaran berdasarkan penilaian ahli media dapat dilihat pada Gambar 3.

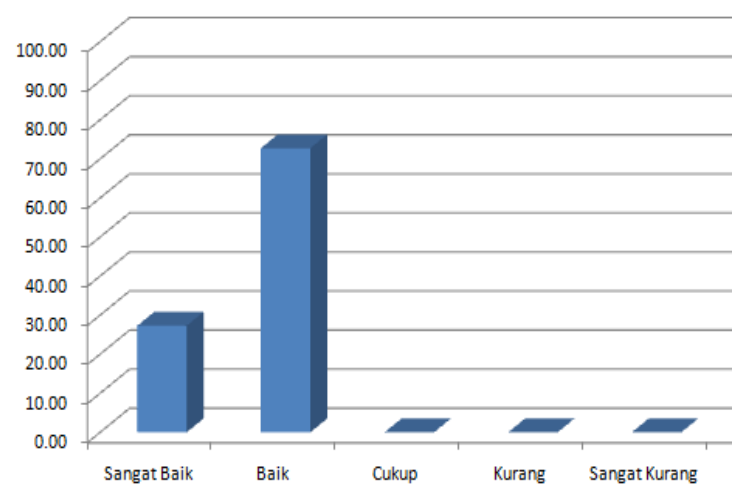

Gambar 3. Grafik Hasil Validasi Ahli Media

Berdasarkan hasil analisis data, dapat dilihat kualitas multimedia pembelajaran menurut ahli media adalah sangat baik dan layak untuk digunakan dalam pembelajaran PIIP Dasar. Namun, terdapat saran dari ahli media yaitu halaman intropada title page diberi info nama pengembang, prodi dan user atau pengguna, memberikan halaman pada menu petunjuk, tombol instrumen gender diubah menjadi simulasi gender, memperjelas keterangan petunjuk pada menu simulasi gender, menu profil dilampirkan foto pengembang, dan menambahkan menu konfirmasi jika keluar dari produk multimedia.

Berdasarkan validasi dari ahli materi dan sesuai dengan kriteria penilaian (Tabel 4).
Penilaian oleh ahli materi tersebut dilakukan dengan menggunakan angket. Angket ahli materi untuk aspek pembelajaran terdiri atas 19 aspek. Diketahui bahwa penilaian kualitas multimedia pembelajaran yang dikembangkan, masuk dalam kriteria "sangat baik" dengan rerata penilaian 4,47. Data tentang penilaian ahli materi dapat dilihat pada Tabel 6 berikut ini

Tabel 6. Hasil Validasi Ahli Materi

\begin{tabular}{lcc}
\hline \multicolumn{1}{r}{ time } & Frek. & Prosentase (\%) \\
\hline Sangat Baik & 9 & 47,37 \\
Baik & 10 & 52,63 \\
Cukup & & \\
Kurang & &
\end{tabular}

Kurang

Sangat kurang

Jumlah

19

100

Kualitas multimedia pembelajaran berdasarkan penilaian ahli materi dapat digambarkan melalui Gambar 4.

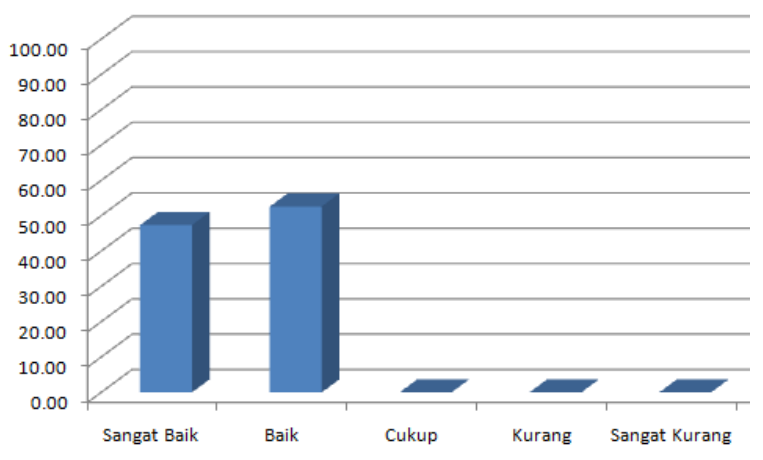

Gambar 4. Grafik Hasil Validasi Ahli Materi

Hasil analisis data menunjukkan bahwa kualitas multimedia pembelajaran menurut ahli materi adalah sangat baik dan layak untuk digunakan dalam pembelajaran. Berdasarkan saran dari ahli materi yaitu mampu memberikan gambaran konkret pada proses simulasi memainkan gender, menambahkan materi agar lebih dalam, dan mengurutkan materi yang diberikan.

\section{Hasil Uji Beta}

Data yang diperoleh dari hasil uji beta digunakan untuk perbaikan produk sebelum dilakukan uji coba kelompok besar. Data yang diperoleh dari hasil uji coba kelompok besar 
digunakan untuk mengukur kualitas multimedia yang dikembangkan dari aspek kemudahan produk untuk dioperasikan, aspek kemudahan produk untuk dipelajari isinya, dan aspek kemenarikan tampilan

Berdasarkan hasil uji beta dan mengacu pada kriteria penilaian (Tabel 4), dapat diketahui penilaian multimedia pembelajaran masuk dalam kategori sangat baik dengan rerata 4,44. Informasi ini dapat dilihat pada Tabel 7.

Tabel 7. Hasil Validasi Uji Beta

\begin{tabular}{lcc}
\hline \multicolumn{1}{c}{ Kategori } & Frek. & Prosentase (\%) \\
\hline Sangat Baik & 44 & 48,89 \\
Baik & 42 & 46,67 \\
Cukup & 4 & 4,44 \\
Kurang & & \\
Sangat kurang & & \\
Jumlah & 90 & 100 \\
\hline
\end{tabular}

Kualitas multimedia pembelajaran berdasarkan uji beta dapat digambarkan melalui grafik pada Gambar 5.

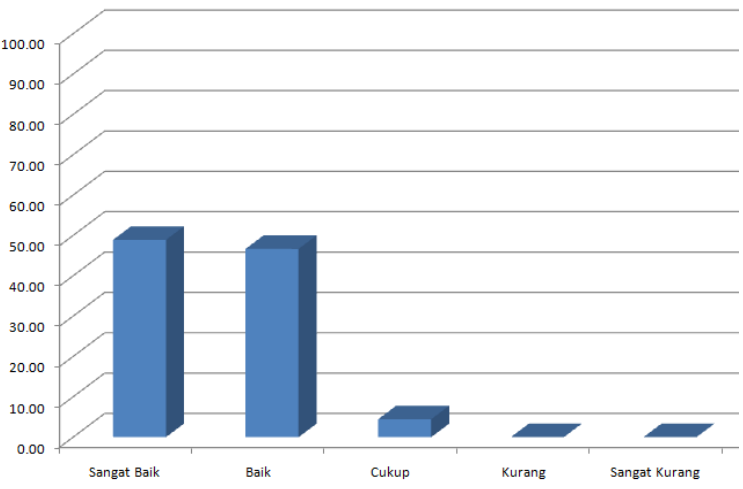

Gambar 5. Grafik Hasil Validasi Uji Beta

Hasil analisis data menunjukkan bahwa kualitas multimedia pembelajaran menurut uji beta adalah "sangat baik" dan layak untuk digunakan dalam pembelajaran. Namun berdasarkan saran yang diberikan, tampilan menu materi pada keterangan gambar gender dapat diperbesar sehingga lebih jelas dan mendetail.

\section{Hasil Uji Sumatif}

Berdasarkan hasil uji sumatif dapat diketahui bahwa penilaian multimedia pembelajaran yang dikembangkan adalah sangat baik dengan rerata penilaian 4,43 informasi hasil uji coba produk dapat dilihat pada Tabel 8 .
Tabel 8. Hasil Validasi Uji Sumatif

\begin{tabular}{lcc}
\hline \multicolumn{1}{c}{ Kategori } & Frek. & Prosentase (\%) \\
\hline Sangat Baik & 244 & 36,97 \\
Baik & 326 & 49,39 \\
Cukup & 90 & 13,64 \\
Kurang & & \\
Sangat kurang & & \\
Jumlah & 660 & 100 \\
\hline
\end{tabular}

Hasil analisis uji sumatif menunjukkan bahwa kualitas multimedia pembelajaran masuk dalam kategori "sangat baik" dan layak untuk digunakan dalam pembelajaran PIIP Dasar.

\section{Analisis Data Pretest dan Posttes}

Pretest dan posttest yang diberikan kepada dua kelas, yaitu kelas eksperimen $\mathrm{X}$ $\mathrm{K} 1$ yang menggunakan multimedia pembelajaran dan kelas kontrol X K3 yang menggunakan media presentasi dimaksudkan untuk melihat kenaikan hasil belajar siswa. Nilai posttest dari kedua kelas diambil dari nilai rata-rata teori (posttest) dan praktik "Memainkan Instrumen Gender Barung". Analisis data pretest kelas eksperimen dapat dilihat pada Tabel 9.

Tabel 9. Analisis Data Pretest/Posttest Kelas Eksperimen

\begin{tabular}{cccc}
\hline No & Pretest & Posttest & Gain \\
\hline 1 & 50 & 78,75 & 28,75 \\
2 & 45 & 71,25 & 26,25 \\
3 & 47,5 & 86,25 & 38,75 \\
4 & 50 & 68,75 & 18,75 \\
5 & 42,5 & 78,75 & 36,25 \\
6 & 37,5 & 80 & 42,5 \\
7 & 45 & 68,75 & 23,75 \\
8 & 52,5 & 86,25 & 33,75 \\
9 & 52,5 & 87,5 & 35 \\
10 & 55 & 76,25 & 21,25 \\
11 & 32,5 & 85 & 52,5 \\
12 & 55 & 85 & 30 \\
13 & 50 & 75 & 25 \\
14 & 45 & 75 & 30 \\
15 & 32,5 & 73,75 & 41,25 \\
16 & 47,5 & 68,75 & 21,25 \\
17 & 35 & 81,25 & 46,25 \\
18 & 52,5 & 73,75 & 21,25 \\
19 & 50 & 88,75 & 38,75 \\
20 & 52,5 & 83,75 & 31,25 \\
21 & 50 & 65 & 15 \\
22 & 42,5 & 78,75 & 36,25 \\
Rerata & 46,47 & 78,01 & 31,53 \\
\hline
\end{tabular}


Berdasarkan Tabel 9 dapat diketahui rerata selisih antara posttest dan pretest adalah 31,53 .

Tabel 10. Analisis Data Pretest/Posttest Kelas Kontrol

\begin{tabular}{cccc}
\hline No & Pretest & Posttest & Gain \\
\hline 1 & 40 & 71,25 & 31,25 \\
2 & 45 & 65 & 20 \\
3 & 55 & 67,5 & 12,5 \\
4 & 50 & 63,75 & 13,75 \\
5 & 47.5 & 68,75 & 21,25 \\
6 & 45 & 73,75 & 28,75 \\
7 & 52,5 & 70 & 17,5 \\
8 & 47,5 & 62,5 & 15 \\
9 & 52,5 & 71,25 & 18,75 \\
10 & 45 & 62.5 & 17,5 \\
11 & 42,5 & 57,5 & 15 \\
12 & 35 & 61,25 & 26,25 \\
13 & 45 & 66,25 & 21,25 \\
14 & 52,5 & 76,25 & 23,75 \\
15 & 42,5 & 66,25 & 23,75 \\
16 & 47,5 & 62,5 & 15 \\
17 & 32,5 & 56,25 & 23,75 \\
18 & 45 & 65 & 20 \\
19 & 52,5 & 71,25 & 18,75 \\
20 & 42,5 & 65 & 22,5 \\
21 & 55 & 73,75 & 18,75 \\
22 & 42,5 & 60 & 17,5 \\
Rerata & 46,13 & 66,25 & 20,11 \\
\hline
\end{tabular}

Berdasarkan Tabel 10 dapat diketahui rerata gain antara posttest dan pretest adalah 20,11 .

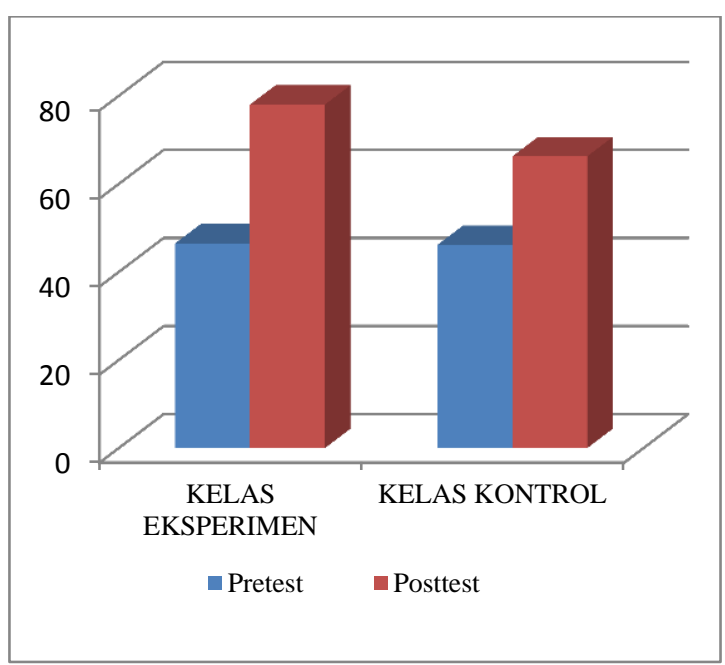

Gambar 6. Grafik Rerata Hasil Evaluasi Nilai Pretest dan Posttest
Hasil analisis kelas eksperimen dan kelas kontrol memperlihatkan bahwa kelas eksperimen yang menggunakan multimedia pembelajaran dapat meningkatkan nilai posttest dari pretest sebesar 31,53, yaitu kenaikan dari 46,47 menjadi 78,01. Untuk kelas kontrol yang menggunakan media presentasi peningkatan nilai posttest dari nilai pretest hanya sebesar 20,11 yaitu dari kenaikan 46,13 menjadi 66,25. Dengan demikian maka dapat dilihat bahwa kenaikan rerata siswa kelas eksperimen sebesar 31,53 lebih tinggi dibandingkan dengan kontrol yang kenaikannya sebesar 20,11. Hasil pretest dan posttest dapat dilihat pada Gambar 6.

\section{SIMPULAN DAN SARAN}

\section{Simpulan}

Hasil penelitian pengembangan ini adalah produk multimedia pembelajaran berbasis komputer pada mata pelajaran PIIP Dasar. Pengembangan multimedia pembelajaran PIIP Dasar berbasis komputer melalui tiga tahap, yaitu: perencanaan, desain, dan pengembangan. Proses perencanaan yaitu mendefinisikan bidang/ruang lingkup penggunaan produk multimedia pembelajaran PIIP Dasar yang diperuntukan pada siswa kelas $\mathrm{X}$ semester 1 dan memuat $\mathrm{SK} / \mathrm{KD}$ yang harus dicapai, mengidentifikasi karakteristik siswa dengan memberikan angket kebutuhan pada siswa kelas $\mathrm{X}$ yang siswa menginginkan produk multimedia yang dapat membantu untuk memahami pelajaran PIIP Dasar, menentukan dan mengumpulkan sumber-sumber untuk mata pelajaran PIIP Dasar dengan materi pokok organologi gender, teknik menabuh instrumen gender barung, notasi gender, dan cengkok genderan lampah II dan melakukan diskusi dengan guru mata pelajaran PIIP Dasar berkaitan dengan materi. Proses desain yaitu mengembangkan isi gagasan utama dengan memilih dan menyeleksi materi yang akan digunakan, melakukan analisis konsep dan tugas dengan menentukan indikator yang ingin dicapai dan merinci materi umum ke dalam komponen materi yang lebih spesifik, pembuatan flowchart dan storyboard untuk menggambarkan alur kerja dan rincian detail apa yang akan dilihat dalam tampilan. Proses pengembangan dimulai dengan menyiapkan semua teks materi yang berkaitan dengan 
materi memainkan instrumen gender barung, menggabungkan setiap bagian yang telah diperoleh, kemudian menyiapkan materi-materi pendukung, membuatan program produk multimedia pembelajaran dengan menggunakan software aplikasi Macromedia flash 8 yang selanjutnya dilakukan uji alpha oleh ahli media dan ahli materi, melakukan revisi pertama terhadap produk yang telah dibuat, melakukan uji beta kepada 3 siswa yang digunakan sebagai dasar revisi akhir, uji coba produk kelompok besar kepada 22 siswa kelas X K1 mata pelajaran PIIP Dasar dan mengadakan pretest dan posttest pada kelas yang menggunakan multimedia pembelajaran dan kelas yang tidak menggunakan multimedia pembelajaran.

Produk multimedia pembelajaran PIIP Dasar, ditinjau dari aspek media termasuk kategori sangat baik berdasarkan hasil validasi ahli media dengan rerata 4.27. Dari aspek materi termasuk kategori sangat baik berdasarkan hasil validasi ahli materi dengan rerata 4.47. Tanggapan siswa berdasarkan hasil uji beta termasuk dalam kategori sangat baik dengan rerata 4.44 dan berdasarkan hasil uji coba/uji sumatif termasuk dalam kategori sangat baik dengan rerata 4.23. Berdasarkan penilaian tersebut maka multimedia pembelajaran yang dikembangkan tersebut layak untuk digunakan pada mata pelajaran PIIP Dasar siswa kelas X di SMK N 1 Kasihan, Bantul.

Multimedia pembelajaran PIIP Dasar yang dikembangkan mampu meningkatkan hasil belajar siswa pada pelajaran PIIP Dasar berdasarkan kenaikan nilai pretest ke posttest. Berdasarkan hasil uji coba pembelajaran diketahui bahwa kenaikan rerata siswa kelas eksperimen sebesar 31.53 lebih tinggi dibandingkan dengan kelas kontrol yang kenaikannya sebesar 20.11 .

\section{Saran}

Berdasarkan beberapa kesimpulan tersebut, maka saran-saran yang bisa dikemukakan yaitu dalam pengembangan multimedia pembelajaran hendaknya dilakukan dengan memperhatikan beberapa tahapan, yaitu: tahap perencanaan pengembangan pembelajaran, tahap desain produk, tahap pengembangan produk, dan tahap evaluasi. Setelah selesai melewati tahap-tahap tersebut, sebuah produk multimedia pembelajaran baru bisa disebarluaskan dan dimanfaatkan secara luas. Hasil pengembangan ini dapat digunakan sebagai salah satu alternatif multimedia pembelajaran PIIP Dasar (memainkan instrumen gender barung) di SMK, baik secara individu maupun kelompok. Guru harus memanfaatkan program multimedia pembelajaran ini dengan baik agar dapat meningkatkan hasil belajar siswa. Multimedia pembelajaran ini hanya memuat satu pokok bahasan. Oleh karena itu, untuk dapat dimanfaatkan secara luas, program pembelajaran ini perlu ditambah dengan pokokpokok bahasan lain. Pengembangan ini hanya dilakukan di SMK yang memiliki fasilitas komputer yang cukup memadai. Salah satu contohnya tersedianya speaker atau earphone agar siswa bisa mendengarkan musik pengiring ataupun narasi yang ada dalam produk multimedia pembelajaran. Penelitian ini masih terbatas pada satu sekolah yaitu di SMK N 1 Kasihan, Bantul, sehingga untuk mengatakan produk tersebut layak untuk pembelajaran perlu dilakukan penelitian lebih lanjut dalam skala besar dan diperluas pada beberapa sekolah baik dalam satu kabupaten/kota maupun dalam beberapa propinsi.

\section{DAFTAR PUSTAKA}

Adeyemo, A. S. (2010). "The Impact of Information Communication and Technology on Teaching and Learning of Physics". International Journal of Educational Research and Technology. Vol.1(2). 48-59

Alessi, S.M., \& Trollip, S.R. (2001). Multimedia for learning: methods and development (3rd Edition). Boston: Allyn and Bacon

Djojonegoro, Wardiman. (1998). Pengembangan Sumberdaya Manusia Melalui Sekolah Menengah Kejuruan. Jakarta: PT. Jayakarta Agung Offset.

Hake, Richard R. (1998). Interactiveengagement versus traditional methods: A six-thousand-student survey of mechanics test data for introductory physics courses. American Journal of Physics (Volume 66). Hlm. 67.

Huang, X., Dedegikas, C., \& Walls, J. (2011). Using multimedia technology to teach modern greek language online in china: Development, implementation, and 
evaluation. European Journal of Open, Distance and E-Learning. 17(1). Pg. 19. Tersedia pada http://www.eurodl.org/materials/contrb/ 2011/HuangDedegikasWalls.pdf (Diakses tanggal 22 Desember 2015).

Hung. (2005). Theories of Learning and Computer-Mediated Instructional Technologies. Journal of Education Media International Vol 2, Pg. 282-287.

Junaidu. S. (2008). Effectiveness of Multimedia in Learning \& Teaching Data Structures Online. Turkish Online Journal of Distance Education-TOJDE, vol. 9, no. 4, pp. 97-107.

Maran, C.M., Selvaraj, C., \& Ravikumar B. (2011). Effectiveness of Multimedia Learning in Higher Education. International Journal of Multimedia Tech- nology. Vol.1 No.2, page 88-92. http://www.files.eric.ed.gov/fulltext/EJ 826093.pdf. (diunduh pada tanggal 19 Desember 2015).

Presiden RI. (2010). Peraturan Pemerintah Nomor 17 Tahun 2010. Tentang Penyelenggaraan dan Pengelolaan Pendidikan.

Sorden. S. D. (2005). A Cognitive Approach to Instructional Design for Multimedia Learning. Informing Science Journal, Vol. 8, pp. 263-279.

Sukardjo. (2008). Hand Out Materi Evaluasi Pembelajaran. Yogyakarta: Jurusan Teknologi Pembelajaran, Program Pascasarjana Universitas Negeri Yogyakarta 